УДК 543.422

\title{
МОДИФИКАЦИЯ АНАЛИТИЧЕСКИХ ФОРМ ПРИ КОСВЕННОМ АТОМНО-АБСОРБЦИОННОМ ОПРЕДЕЛЕНИИ ФОСФОРА
}

\author{
(C) 2018 А. С. Алемасова, Н. Д. Щепина, А. Н. Чуприна, А. С. Сергеева, А. В. Добрыдин \\ Донецкий наџиональный университет, ул. Университетская, 24, 83001 Донецк, Украина \\ e-mail: alemasovaa@gmail.com \\ Поступила в редакцию 06.08.2018
}

\begin{abstract}
Аннотация. Модифицированы аналитические формы для косвенного атомно-абсорбционного определения фосфора: 11-молибдожелезофосфатный гетерополикомплекс и ионный ассоциат фенантролината меди(II) (3:1) с гетерополианионом фосфора, которые обеспечивают повышенную селективность и чувствительность определения. Разработана методика косвенного пламенного атомно-абсорбционного определения фосфора в воде, отличающаяся от известных улучшенной воспроизводимостью, экспрессностью, селективностью. Относительное стандартное отклонение не превышает 0.06, продолжительность определения составляет 35 мин.
\end{abstract}

Ключевые слова: фосфор, косвенное определение, атомно-абсорбционная спектрометрия.

DOI: https://doi.org/10.17308/kcmf.2018.20/577

\section{ВВЕДЕНИЕ}

Описано огромное количество методик определения фосфора в самых разнообразных объектах. И, тем не менее, разработка новых, более совершенных методик не утратила актуальность вследствие недостаточной чувствительности и селективности существующих методик, их трудоемкости [1-5].

Известны косвенные амплификационные спектрофотометрические методики определения фосфора в виде гетерополианиона 12-го ряда по атомам лиганда, использующие выгодный стехиометрический фактор [6-11]. Несмотря на потенциально возможную высокую чувствительность амплификационных методик с использованием гетерополикислот, на практике они не получили распространения. Косвенные методики являются многостадийными, включают сложные по выполнению операции разделения. Поэтому общая воспроизводимость таких косвенных методик значительно хуже, чем прямых. Избыток реагента, который нужно отделять от комплекса определяемого элемента, составляет от $10^{6}: 1$ и выше. Ясно, что выполнить точно такое разделение экстракцией очень сложно и эти сложности непропорционально сильно возрастают при увеличении избытка реагента. Трудоемкость методики увеличивается также в силу не- обходимости дополнительного контроля и очистки реагентов.

Существенно более перспективным является использование косвенных методов в атомно-спектроскопических методиках определения фосфора. В этом случае амплификация, во-первых, происходит за счет использования эффекта умножения, но только в том случае, когда измеряют аналитический сигнал атомов молибдена гетерополианиона (ГПА). Более значительным является выигрыш в чувствительности за счет замены методики определения центрального иона на более чувствительную методику определения атома/атомов лиганда.

Следовательно, актуальной задачей при разработке косвенных методик определения фосфора становится подбор условий, в которых стало бы возможным использование наиболее подходящего по своим химико-аналитическим характеристикам атома лигандной сферы гетерополианиона.

В табл. 1 сопоставлена чувствительность атомно-спектроскопических методик определения фосфора и элементов, составляющих лигандную сферу. Величины пределов обнаружения приведены по [12, 13].

Из данных табл. 1 видно, что наибольший выигрыш в чувствительности достигается при исполь- 
Таблица 1. Сопоставление чувствительности (инструментальный предел обнаружения ПрО = $3 \sigma$, мкг/л) атомно-спектроскопических методик определения фосфора и элементов, способных занимать место в лигандной сфере ГПА (с учетом коэффициента умножения 12 в случае Мо и W)

[Table 1. Comparison of sensitivity (instrument detection limit LOD $=3 \sigma, \mu \mathrm{g} / \mathrm{l}$ ) of phosphorus determination using atomic spectroscopic methods and elements supplanting a place in the ligand sphere of HPA (taking into account the multiplication factor 12 for Mo and $\mathrm{W}$ )]

\begin{tabular}{|c|c|c|c|}
\hline $\begin{array}{c}\text { Метод атомной спектроскопии } \\
\text { [Atomic spectroscopy method] }\end{array}$ & $\begin{array}{l}\text { Предел обнаруже- } \\
\text { ния фосфора } \\
\text { [Phosphorus limit of } \\
\text { detection] }\end{array}$ & $\begin{array}{c}\text { Элемент лигандной } \\
\text { сферы ГПА, ПрО [Тhe } \\
\text { ligand sphere HPA } \\
\text { element, LOD] }\end{array}$ & $\begin{array}{c}\text { Относительный выигрыш } \\
\text { в чувствительности } \\
\text { [The relative gain in } \\
\text { sensitivity] } \\
\end{array}$ \\
\hline \multirow{10}{*}{$\begin{array}{l}\text { Пламенный атомно-абсорбцион- } \\
\text { ный } \\
\text { [Flame atomic absorption spectrom- } \\
\text { etry] }\end{array}$} & \multirow{10}{*}{75000} & Mo 45 & 20000 \\
\hline & & W 1500 & 600 \\
\hline & & V 60 & 1250 \\
\hline & & Bi $30\left(0.03^{*}\right)$ & $2500\left(2.5 \cdot 10^{6}\right)$ \\
\hline & & $\mathrm{Fe} 5$ & 15000 \\
\hline & & Co 9 & 8300 \\
\hline & & $\mathrm{Zn} 1,5$ & 50000 \\
\hline & & $\mathrm{Cu} 1$ & 75000 \\
\hline & & $\mathrm{Ni} 4$ & 20000 \\
\hline & & Mn 1 & 75000 \\
\hline \multirow{2}{*}{$\begin{array}{c}\text { Рентгено-флуоресцентный } \\
\text { [X-ray fluorescence] }\end{array}$} & \multirow[b]{2}{*}{$\begin{array}{l}240(30 \text { мкг/г) } \\
{[240(30 \mu \mathrm{g} / \mathrm{g})]}\end{array}$} & Mo 100 & 60 \\
\hline & & $\begin{array}{c}\mathrm{Bi} 7(0.7 \mathrm{мг} / \mathrm{\kappa г}) \\
{[\mathrm{Bi} 7(0.7 \mathrm{mg} / \mathrm{kg})]}\end{array}$ & 35 \\
\hline \multirow{4}{*}{$\begin{array}{c}\text { Атомно-эмиссионный с индуктив- } \\
\text { но связанной плазмой } \\
\text { [Inductively coupled plasma atomic } \\
\text { emission spectroscopy] }\end{array}$} & \multirow{4}{*}{4} & Mo 0.5 & 100 \\
\hline & & Bi 1 & 4 \\
\hline & & Zn 0.2 & 20 \\
\hline & & $\mathrm{Zn} 0.2$ & 7.5 \\
\hline \multirow{3}{*}{$\begin{array}{c}\text { Электротермический атомно- } \\
\text { абсорбционный } \\
\text { [Electrothermal atomic absorption } \\
\text { spectroscopy] }\end{array}$} & \multirow{3}{*}{130} & Mo 0.03 & 40000 \\
\hline & & Bi 0.05 & 2600 \\
\hline & & Zn 0.02 & 6500 \\
\hline \multirow{3}{*}{$\begin{array}{c}\text { Macc-спектроскопия с индуктивно } \\
\text { связанной плазмой } \\
\text { [Inductively coupled plasma mass } \\
\text { spectrometry] }\end{array}$} & \multirow{3}{*}{0.1} & Mo 0.001 & 1200 \\
\hline & & Bi 0.0006 & 170 \\
\hline & & $\mathrm{Pb} \mathrm{0.00004**}$ & 2500 \\
\hline
\end{tabular}

зовании элементов лигандной сферы гетерополианиона меди, марганца, железа, цинка (counter-ion) и пламенного атомно-абсорбционного метода измерения концентрации металла-индикатора.

Целью данной работы являлось исследование аналитических и метрологических характеристик косвенных атомно-абсорбционных методик определения фосфора с использованием новых аналитических форм и металлов-индикаторов меди и железа.

Металлсодержащие аналитические формы фосфора можно получить в результате:

1. образование тройных металлзамещённых ГПА фосфора общей формулы $\mathrm{PZMo}_{11} \mathrm{O}_{40}^{\mathrm{n}-}$ $(\mathrm{Z}=\mathrm{Ti}(\mathrm{IV}), \mathrm{Bi}(\mathrm{III}), \mathrm{Sb}(\mathrm{III}), \mathrm{Fe}(\mathrm{III})$ и др.) и экстракционное отделение от избытка ионов замещенного металла.
2. образование и извлечение ионного ассоциата металлсодержащих катионов и фосфоромолибдатаниона. Например, описан косвенный атомно-абсорбционный метод определения фосфора в природных водах с использованием флотации ионной пары [2-(5-хлор-2-пиридилазо)-5-диэтиламинофенолят] кобальта(II) - молибдофосфат бутилацетатом [14].

Однако из данных табл. 1 следует, что выигрыш в чувствительности при использовании в качестве металла-индикатора кобальта значительно меньше, чем, например, при использовании меди или марганца. В то же время известно, что медь(II) образует устойчивые катионные комплексы со многими реагентами, в том числе с $о$-фенантролином (Phen). Описаны комплексы с соотношением металл: ли- 
ганд $1: 1,1: 2$ и $1: 3\left(\lg \beta_{3}=5.35[15]\right)$, и этот катион может быть использован для образования ионной пары с молибдофосфат-анионом.

\section{МЕТОДИКА ЭКСПЕРИМЕНТА}

В работе использовали реактивы квалификации х.ч. и выше.

Исходный стандартный раствор фосфора с концентрацией 1.000 мг/мл готовили из $\mathrm{KH}_{2} \mathrm{PO}_{4}$ по [16]. Рабочие растворы готовили разбавлением в мерной колбе соответствующей аликвоты исходного раствора дистиллированной водой в день использования.

Фенантролинатный комплекс меди(II) с соотношением медь : фенантролин $=1: 3\left(\left[\mathrm{CuPhen}_{3}\right]^{2+} \cdot \mathrm{SO}_{4}{ }^{2-}\right)$ готовили растворением в воде навески 0.0338 г $o$-фенантролина с добавлением 1 капли концентрированной серной кислоты с последующим растворением в этом растворе навески 0.0141 г $\mathrm{CuSO}_{4} \cdot 5 \mathrm{H}_{2} \mathrm{O}$. Раствор переносили в мерную колбу вместимостью 1 л и разбавляли водой до метки.

При использовании в качестве аналитической формы ионного ассоциата фенантролинатного комплекса меди(II) с молибдофосфат-анионом методика работы была следующая. В делительную воронку вместимостью 100 мл помещали 5.0 мл 0.005 $\mathrm{M}$ раствора молибдата аммония $\left(\mathrm{NH}_{4}\right)_{2} \mathrm{MoO}_{4}$, добавляли 1 каплю концентрированной серной кислоты, 0.1 мл рабочего раствора фосфора(V) с концентрацией 0.100 мг/мл. Далее вносили 10 мл раствора комплекса $\left(\mathrm{CuPhen}{ }_{3}\right)^{2+} \mathrm{SO}_{4}{ }^{2-}$, создавали необходимую кислотность, выдерживали 15 минут для установления равновесия. Образующийся ионный ассоциат флотируется рядом органических растворителей, наилучшим из которых является изоамиловый спирт. Добавляли 10 мл флотореагента и встряхивали 2 минуты до установления равновесия между фазами.

Органический слой переносили в фарфоровую чашку, осторожно испаряли на электроплитке растворитель, озоляли концентрат. Сухой остаток растворяли в 1 мл концентрированной азотной кислоты. Охлажденные растворы количественно переносили в градуированные пробирки вместимостью 10 мл и определяли концентрацию меди пламенным атомно-абсорбционным методом.

При использовании в качестве аналитической формы тройного железозомещенного гетерополианиона фосфора методика работы была следующей: в делительную воронку вместимостью 100 мл вносили 1.0 мл рабочего раствора фосфора(V) с концентрацией 1.00 мг/л и 1.0 мл 0.02 М раствора мо- либдата аммония. К полученному раствору добавляли 0.2 мл $1 \mathrm{M}$ раствора уксусной кислоты для предотвращения гидролиза железа(III) и 4.5 мл стандартного раствора железа(III) с концентрацией 1 мг/мл, устанавливали необходимую кислотность, разбавляли дистиллированной водой до 50 мл, выдерживали 15 минут для установления равновесия. Измеряли равновесное значение $\mathrm{pH}$ с использованием иономера ИВ-160М (стеклянный и хлорсеребряный электроды). Кислотность регулировали в диапазоне значений $\mathrm{pH}=1.6-3.4$. Прибавляли 5 мл органического растворителя. В случае изопропанола, этилацетата и метилэтилкетона дополнительно для полноты разделения фаз прибавляли 12.0 г сульфата аммония (высаливателя). Проводили экстракцию в течении 2 минут, оставляли на 10 минут для полного расслоения фаз. Концентрацию железа определяли непосредственно в экстракте атомно-абсорбционным методом. Учитывали величину холостого опыта.

Измерение аналитического сигнала проводили на атомно-абсорбционном спектрофотометре Сатурн-3 на резонансных длинах волн 324.8 нм (медь) 248.3 нм (железо) с использованием стехиометрического пламени ацетилен-воздух.

\section{РЕЗУЛЬТАТЫ И ИХ ОБСУЖДЕНИЕ}

При использовании в качестве аналитической формы ионного ассоциата фенантролинатного комплекса меди(II) с молибдофосфат-анионом исследованы оптимальные условия флотации ионного ассоциата: кислотность раствора, концентрация молибдата аммония и фенантролината меди(II).

Установлено, что максимальная абсорбционность меди (и, следовательно, максимальная степень флотации ионного ассоциата) наблюдается в интервале $\mathrm{pH} 2.5-3.5$, что обусловлено, вероятно, зависимостью состояния фосфоромолибдат-иона в растворе от $\mathrm{pH}$.

Состояние фосфоромолибдата в водных растворах различных концентраций осложнено процессами полимеризации молибдата, который находится в равновесии с гетерополикомплексом, а в растворах больших концентраций, возможно, и полимеризацией гетерополикислоты [17-20].

Так, в сильнокислых растворах 12-молибдофосфат разлагается с образованием молибденилионов:

$$
\mathrm{PMo}_{12} \mathrm{O}_{40}{ }^{3-}+9 \mathrm{H}^{+} \leftrightarrow \mathrm{H}_{3} \mathrm{PO}_{4}+6\left(\mathrm{HMo}_{2} \mathrm{O}_{6}\right)^{+}
$$

В разбавленных растворах фосфоромолибдат при небольшой кислотности в результате гидролиза образует 6-фосфоромолибдат: 
$\mathrm{PMo}_{12} \mathrm{O}_{40}^{3-}+6 \mathrm{H}_{2} \mathrm{O} \leftrightarrow$

$\leftrightarrow \mathrm{H}_{3} \mathrm{Mo}_{6} \mathrm{O}_{21}{ }^{3-}+\left(\mathrm{H}_{2} \mathrm{PO}_{4}\right)\left(\mathrm{H}_{3} \mathrm{Mo}_{6} \mathrm{O}_{21}\right)^{4-}+4 \mathrm{H}^{+}$

Полярографическими исследованиями $0.1 \mathrm{M}$ по Мо растворов фосфоромолибдатов показано, что 12-фосфоромолибдат образуется лишь при pH ниже 2 , а в пределах $2<\mathrm{pH}<5$ существует 11 -фосфоромолибдат, который при $\mathrm{pH}>6$ гидролизуется в $\left[\left(\mathrm{PO}_{4}\right)_{2}\left(\mathrm{MoO}_{3}\right)_{5}\right]^{6-}$.

В то же время авторы [18] утверждают, что при $\mathrm{pH}=3.0$ состав комплекса соответсвует, повидимому, отношению Мо:P = 12:1.

Такое же утверждение высказано авторами статьи [19]: при изменении кислотности от 3.4 до 1.0 и ниже образуется ряд фосфорномолибденовых комплексов с различным соотношение [Mo]:[Р]. При $\mathrm{pH}=3.0$ образуется только один гетерополикомплекс, в котором отношение Мо: $\mathrm{P}=12: 1$. Повышение кислотности приводит к образованию других комплексов с иным, большим, чем 12:1, отношение Мо:Р. Ниже $\mathrm{pH} 3$ по мере роста кислотности раствора образуется смесь гетерополикислот с преобладанием комплекса, состав которого соответствует отношению Мо: $\mathrm{P}=16: 1$. Этому комплексу авторы приписывают формулу $\mathrm{H}_{3}\left[\mathrm{P}\left(\mathrm{Mo}_{4} \mathrm{O}_{13}\right)_{4}\right] \cdot \mathrm{nH}_{2} \mathrm{O}$.

В дальнейшем для поддержания необходимой кислотности использовали формиатный буферный раствор с $\mathrm{pH}=3.00$.

Так как высокозарядный гетерополианион фосфора образуется в избытке молибдата аммония, то и флотационное отделение его ионного ассоциата с фенантролинатом меди(II) также тре- бует его избытка. Было установлено, что максимальное значение аналитического сигнала меди наблюдается при 80-кратном избытке молибдата аммония.

Методом насыщения установлено соотношение меди к фосфору во флотируемом ассоциате, которое составляет $1: 1$. Это дает возможность готовить градуировочные растворы, не проводя известные количества фосфат-иона через описанную выше методику образования и флотации ионного ассоциата, а простым разбавлением стандартного раствора меди(II).

Для подтверждения состава гетерополианиона в ионном ассоциате был использован метод ИКспектроскопии, который широко используется в химии гетерополикомплексов для установления типа или структурных особенностей ГПК. Органический концентрат выдерживали в вакуумном эксикаторе до полного удаления растворителя и регистрировали ИК-спектр на спектрометре Specord-75IR в таблетках $\mathrm{KBr}$.

Наиболее характерным является участок спектра 1000-400 см $\mathrm{cm}^{-1}$. Отнесение частот характеристичных полос поглощения в ИК-спектре ионного ассоциата представлено в табл. 2.

Таким образом, исходя из данных ИК-спектроскопии, можно предполагать, что в состав ионного ассоциата входит 12-молибдофосфат-анион.

На основании этих данных и с учетом состояния фосфоромолибдат-иона в растворе можно предположить механизм протекающих процессов и состав флотируемого соединения:

Таблица 2. Отнесение частот характеристических полос поглощения в ИК-спектре ассоциата фенантролинат меди(II)-ГПА

[Table 2. Frequency assignment of the characteristic absorption bands in the IR spectrum of ion associate of copper(II) phenantrolinate-HPA]

\begin{tabular}{|c|c|c|}
\hline $\begin{array}{l}\text { Частота полосы поглощения в } \\
\text { ИК-спектре ионного ассоциата } \\
\text { [The absorption bands frequency } \\
\text { in ion associate IR spectrum] }\end{array}$ & $\begin{array}{l}\text { Частота характеристичес- } \\
\text { кой полосы по [21] } \\
\text { [The characteristic band } \\
\text { frequency by [21]] }\end{array}$ & $\begin{array}{l}\text { Отнесение полос } \\
\text { [Assignments] }\end{array}$ \\
\hline 1060 & 1063 & $v(\mathrm{P}-\mathrm{O})[21,22,23]$ \\
\hline 960 & $965(955)$ & $\begin{array}{c}\mathrm{v}(\mathrm{Mo}=\mathrm{O}) \text { концевые })[21,23,24] \\
[\mathrm{v}(\mathrm{Mo}=\mathrm{O}) \text { end })[21,23,24]]\end{array}$ \\
\hline 856 & 880 & $\begin{array}{l}v(\mathrm{Mo} / \mathrm{O} \backslash \mathrm{Mo}) \text { угловые }[19,24] \\
{[\mathrm{v}(\mathrm{Mo} / \mathrm{O} \backslash \mathrm{Mo}) \text { corner }[19,24]]}\end{array}$ \\
\hline 790 & $805(780)$ & $\begin{array}{c}\text { v(Mo-O-Mo) мостиковые } \\
v(\text { Mo-O-Mo }) v_{\text {as }}\left(\mathrm{Mo-O}_{\mathrm{p}}\right)[22] \\
{\left[\mathrm{v}(\mathrm{Mo}-\mathrm{O}-\mathrm{Mo}) \text { bridge } \mathrm{v}(\mathrm{Mo}-\mathrm{O}-\mathrm{Mo}) v_{\mathrm{as}}\left(\mathrm{Mo}_{\mathrm{p}}\right)[22]\right]}\end{array}$ \\
\hline 595 & $612(592)$ & $v(\mathrm{O}-\mathrm{P}-\mathrm{O})[21,22,23]$ \\
\hline 510 & 505 & \multirow{2}{*}{$v(\mathrm{O}-\mathrm{P}-\mathrm{O})[21]$} \\
\hline 455 & 464 & \\
\hline
\end{tabular}




$$
\begin{gathered}
{\left[\mathrm{Cu}(\mathrm{II})\left(\mathrm{H}_{2} \mathrm{O}\right)_{6}\right]^{2+}+3 \mathrm{Phen}_{2} \cdot \mathrm{H}_{2} \mathrm{SO}_{4} \rightarrow} \\
\rightarrow\left\{\left[\mathrm{Cu}(\mathrm{II})(\mathrm{Phen})_{3}\left(\mathrm{H}_{2} \mathrm{O}\right)\right]^{2+} \cdot \mathrm{H}_{2} \mathrm{SO}_{4}\right\}+5 \mathrm{H}_{2} \mathrm{O}+2 \mathrm{H}_{2} \mathrm{SO}_{4} \\
\left\{\left[\mathrm{Cu}(\mathrm{II})(\mathrm{Phen})_{3}\left(\mathrm{H}_{2} \mathrm{O}\right)\right]^{2+} \cdot \mathrm{H}_{2} \mathrm{SO}_{4}\right\}+\mathrm{PMo}_{12} \mathrm{O}_{40}{ }^{3-} \rightarrow \\
\rightarrow\left\{\left[\mathrm{Cu}(\mathrm{II})(\mathrm{Phen})_{3}\left(\mathrm{H}_{2} \mathrm{O}\right)\right]^{2+} \cdot \mathrm{HPMo}_{12} \mathrm{O}_{40}{ }^{2-}\right\}+\mathrm{HSO}_{4}^{-}
\end{gathered}
$$

С целью исследования возможности применения новой аналитической формы в косвенном электротермическом атомно-абсорбционном методе были исследованы возможные влияния компонентов флотируемого ассоциата на аналитический сигнал меди при атомизации в графитовой печи. Измерения проводили при полной оптимизации условий атомизации, близких к условиям концепции температурно-стабилизированной печи с платформой. Показано, что $\mathrm{H}_{2} \mathrm{PO}_{4}^{-}, \mathrm{MoO}_{4}^{2-}$, Phen, взятые в соотношениях, соответствующих соотношениям меди и мешающих компонентов в ионном ассоциате, практически не влияют на абсорбционность меди. Это позволяет сделать вывод о перспективности аналитической формы ионного ассоциата
$\left.(\mathrm{CuPhen})_{3}\right)^{2+} \cdot$ ГПА ${ }^{2-}$ при косвенном атомно-абсорбционном определении фосфора.

Существенным недостатком экстракционно-атомно-абсорбционных методик определения фосфора с использованием замещенных гетерополианионов структуры Кеггина является их низкая селективность. Определению фосфора мешают мышьяк, кремний, цирконий, ниобий, вольфрам, титан и др. С учетом этого было исследовано влияние сопутствующих компонентов на степень извлечения (флотации) ионного ассоциата $\left[\mathrm{CuPhen}_{3}\right]^{2+} \cdot \mathrm{HPMo}_{12} \mathrm{O}_{40}{ }^{2-}$. Влияние оценивали по изменению аналитического сигнала меди, измеряемого в пламени ацетилен-воздух, после кислотной минерализации флотата концентрированной азотной кислотой. Были исследованы вещества, обычно сопутствующие фосфору в природных объектах и способные образовывать гетерополианионы. Полученные данные обобщены в табл. 3.

Таблица 3. Влияние посторонних веществ на результаты косвенного атомно-абсорбционного определения фосфора с использованием металла-индикатора меди и ионного ассоциата $\left[\mathrm{CuPhen}_{3}\right]^{2+}$.ГПА в качестве

\begin{tabular}{|c|c|c|}
\hline $\begin{array}{c}\text { Добавка } \\
\text { [Additive] }\end{array}$ & $\begin{array}{c}\text { Количество, мкг } \\
\text { [Amount, } \mu \mathrm{g} \text { ] }\end{array}$ & $\begin{array}{l}\text { Относительная ошибка косвенного определения } \\
\text { фосфора, \% * } \\
\text { [The relative error of phosphorus indirect determination, \% *] }\end{array}$ \\
\hline \multirow{2}{*}{$\mathrm{NaCl}$} & 500 & -1 \\
\hline & 5000 & -2 \\
\hline $\mathrm{KCl}$ & 5000 & -1 \\
\hline $\mathrm{NaSCN}$ & 500 & -5 \\
\hline $\mathrm{MgCl}_{2}$ & 5000 & -1 \\
\hline \multirow{2}{*}{$\mathrm{CaCl}_{2}$} & 500 & +4 \\
\hline & 5000 & -8 \\
\hline \multirow{2}{*}{$\left(\mathrm{NH}_{4}\right)_{2} \mathrm{Fe}\left(\mathrm{SO}_{4}\right)_{2}$} & 500 & -19 \\
\hline & 5000 & -20 \\
\hline \multirow{2}{*}{$\mathrm{Na}_{2} \mathrm{HAsO}_{4}$} & 10 & +14 \\
\hline & 100 & +20 \\
\hline \multirow{2}{*}{$\mathrm{Na}_{2} \mathrm{SiO}_{3}$} & 10 & -34 \\
\hline & 100 & -56 \\
\hline \multirow{2}{*}{$\mathrm{Na}_{2} \mathrm{~S}_{2} \mathrm{O}_{3}$} & 500 & 0 \\
\hline & 5000 & +4 \\
\hline $\mathrm{KNO}_{3}$ & 5000 & 0 \\
\hline $\mathrm{NH}_{4} \mathrm{VO}_{3}$ & 10 & -54 \\
\hline $\mathrm{CdSO}_{4}$ & 5000 & -6 \\
\hline \multirow{2}{*}{$\mathrm{Na}_{2} \mathrm{WO}_{4}$} & 10 & -3 \\
\hline & 100 & +2 \\
\hline
\end{tabular}
аналитической формы (концентрация фосфора 10 мкг)

[Table 3. The extraneous substances influence on the results of phosphorus indirect atomic absorption determination using copper as metal-indicator and ion associate of $\left[\mathrm{CuPhen}_{3}\right]^{2+} \cdot \mathrm{HPA}$ as analytical form]

* Относительную ошибку косвенного определения фосфора оценивали по формуле $\left(m-m_{0}\right) / m_{0} \cdot 100 \%$, где $m-$ найденная масса фосфора в растворе с добавкой, $m_{0}$ - найденная масса фосфора в растворе без добавки.

*[The relative error of indirect phosphorus determination was calculated according to formula $\left(m-m_{0}\right) / m_{0} \cdot 100 \%$, where $m$ - phosphorus mass found in the presence of the additives in solution, $m_{0}$ - phosphorus mass found without the additives in solution] 
Установлено, что определению фосфора не мешают 500-кратный избыток $\mathrm{Na}^{+}, \mathrm{K}^{+}, \mathrm{Ca}^{2+}, \mathrm{Mg}^{2+}$, $\mathrm{W}(\mathrm{VI}), \mathrm{S}_{2} \mathrm{O}_{3}^{2-}, \mathrm{NO}_{3}^{-}, \mathrm{Cd}^{2+}$. Новая аналитическая форма обеспечивает большую селективность определения фосфора. Например, в экстракционно-фотометрической методике (фосфоромолибденовую кислоту отделяют от избытка молибдата смесью $80 \%$ хлороформа и $20 \%$ н-бутанола) определению мешают $\mathrm{S}_{2} \mathrm{O}_{3}{ }^{2-}, \mathrm{Pb}^{2+}, \mathrm{SCN}^{-}, \mathrm{Bi}^{3+}, \mathrm{Cr}_{2} \mathrm{O}_{7}{ }^{2-}$ и др. [25].

При исследовании аналитической формы на основе тройного металлзамещённого ГПА фосфора с металлом-индикатором железо(III) для отделения аналитической формы использовали экстракцию. В качестве экстрагентов были исследованы растворители различной природы - спирты, эфиры, кетоны. Результаты представлены в табл. 4.

Из данных табл. 4 видно, что сложные эфиры не извлекают тройной железозамещённый комплекс, степень извлечения спиртами возрастает при увеличении числа атомов углерода в спирте, однако наилучшими экстрагентами являются бутан-2он и циклогексанон.

С целью выбора наилучшего экстрагента было проведено исследование влияния органического растворителя на чувствительность атомно-абсорбционного определения железа. Исследовали изменение величины аналитического сигнала железа $\Delta \mathrm{A}=\mathrm{A}_{\mathrm{o}} / \mathrm{A}_{\text {в }}$, где $\mathrm{A}_{\mathrm{o}}-$ абсорбционность железа в

Таблица 4. Степень экстракции тройного железозамещённого ГПА органическими растворителями

[Table 4. The extraction rate of triple iron-substituted HPA using organic solvents]

\begin{tabular}{|c|c|}
\hline $\begin{array}{c}\text { Органический } \\
\text { растворитель } \\
\text { [The organic solvent] }\end{array}$ & $\begin{array}{c}\text { Степень экстракции } R, \% \\
\text { [Extraction rate } R, \%]\end{array}$ \\
\hline $\begin{array}{l}\text { 2-Пропанол } \\
\text { [Propan-2-ol] }\end{array}$ & 30 \\
\hline $\begin{array}{c}\text { 1-Бутанол } \\
\text { [Butan-1-ol] }\end{array}$ & 35 \\
\hline $\begin{array}{l}\text { 2-Бутанол } \\
\text { [Butan-2-ol] }\end{array}$ & 50 \\
\hline $\begin{array}{l}\text { Циклогексанол } \\
\text { [Cyclohexanol] }\end{array}$ & 78 \\
\hline $\begin{array}{c}\text { Этилацетат } \\
\text { [Ethyl acetate] }\end{array}$ & 0 \\
\hline $\begin{array}{c}\text { Бутилацетат } \\
\text { [Butyl acetate] }\end{array}$ & 0 \\
\hline $\begin{array}{l}\text { Циклогексанон } \\
\text { [Cyclohexanone] }\end{array}$ & 91 \\
\hline $\begin{array}{c}\text { Бутан-2-он } \\
\text { [Butan-2-one] }\end{array}$ & 98 \\
\hline
\end{tabular}

органическом растворителе, $\mathrm{A}_{\text {в }}$-абсорбционность в водном растворе.

Аналитический сигнал железа по сравнению с водным раствором в бутан-2-оне увеличивается в 1.4 раза, а в циклогексаноне уменьшается в 1.3 раза. Большая эффективность бутан-2-она, вероятно, обусловлена его физическими характеристиками. Вязкость бутан-2-она в 2 раза ниже, чем у воды и в 6 раз ниже, чем у циклогексанона. Поверхностное натяжение у бутан-2-он в 3 раза ниже, чем у воды и в 1.4 раза ниже, чем у циклогексанона. Более низкая температура кипения бутан-2-она $\left(79.6^{\circ} \mathrm{C}\right)$, вероятно, способствует формированию более мелкодисперсных частиц аэрозоля. Причина снижения сигнала железа в присутствии циклогексанона связана, вероятно, с увеличением вязкости раствора, что делает капли аэрозоля кинетически более инертными и влияет на эффективность и скорость распыления исследуемого раствора в пламя.

На основе проведенных исследований была разработана методика косвенного атомно-абсорбционного определения фосфора в природных водах.

К 50.0 мл пробы воды, отобранной по [16], прибавляют 1.0 мл $0.02 \mathrm{M}$ раствора $\left(\mathrm{NH}_{4}\right)_{6} \mathrm{Mo}_{7} \mathrm{O}_{24} \cdot 4 \mathrm{H}_{2} \mathrm{O}$, 0.5 мл стандартного раствора $\mathrm{FeCl}_{3}$ с концентрацией 0.1 мг/мл в $2 \mathrm{M}$ растворе $\mathrm{HCl}$ и 0.2 мл $1 \mathrm{M}$ раствора $\mathrm{CH}_{3} \mathrm{COOH}$. С помощью $1 \mathrm{M}$ раствора $\mathrm{NaOH}$ устанавливают $\mathrm{pH}=1.6-3.4$. Через 15 минут добавляют 5.0 мл бутан-2-она и проводят экстракцию в течение 2 минут. К полученному экстракту для разделения фаз прибавляют 12.0 г высаливателя сульфата аммония. Фазы разделяют, и экстракт распыляют в пламя ацетилен-воздух. Градуировочные экстракты готовят, проводя через все стадии анализа, как описано выше, стандартные растворы фосфора(V) с концентрацией 0.005-0.10 мг/л. Полученные данные представлены в табл. 5.

Проверку правильности результатов проводили их сравнением с результатами определения по стандартной фотометрической методике по [16]. Стандартная методика отличается от предложенной меньшей чувствительностью, худшей воспроизводимостью, определению мешают: железо при концентрации, превышающей 10 мг/л, растворимые силикаты при содержании более 5 мг/л, нитриты (в пересчете на азот) 3.29 мг/л. При анализе природных вод с высокой цветностью (выше 90 окрашенные органические вещества мешают спектрофотометрическому определению фосфат-ионов и в виде желтого молибдофосфата и в виде восстановленной синей формы. Этих недостатков лишена предложенная методика. 
Таблица 5. Определение содержания фосфора в водах $(n=3 ; P=0.95)$

[Table 5. Phosphorus determination in water $(n=3 ; P=0.95)$ ]

\begin{tabular}{|c|c|c|c|c|}
\hline \multirow{3}{*}{$\begin{array}{c}\text { Объект исследования } \\
\text { [Object of study] }\end{array}$} & \multicolumn{4}{|c|}{$\begin{array}{c}\text { Найдено, мг/л } \\
\text { [Found, mg/l] }\end{array}$} \\
\hline & \multicolumn{2}{|c|}{$\begin{array}{c}\text { косвенным атомно-абсорбционным } \\
\text { методом по металлу-индикатору железу } \\
\text { [indirect atomic absorption method with } \\
\text { iron as metal-indicator] }\end{array}$} & \multicolumn{2}{|c|}{$\begin{array}{l}\text { спектрофотометрическим методом } \\
\text { по ИСО [16] } \\
\text { [spectrophotometric method according } \\
\text { to ISO [16]] }\end{array}$} \\
\hline & $\bar{C} \pm \frac{t \cdot S}{\sqrt{n}}$ & $\mathrm{~S}_{\mathrm{r}}$ & $\bar{C} \pm \frac{t \cdot S}{\sqrt{n}}$ & $S_{\mathrm{r}}$ \\
\hline $\begin{array}{c}\text { Питьевая вода } \\
\text { [Drinking water] }\end{array}$ & $0.14 \pm 0.02$ & 0.06 & $0.12 \pm 0.03$ & 0.1 \\
\hline $\begin{array}{l}\text { Колодезная вода } \\
\text { [Well water] }\end{array}$ & $0.33 \pm 0.04$ & 0.05 & $0.36 \pm 0.08$ & 0.09 \\
\hline
\end{tabular}

Результаты определений содержания фосфатионов в водах, полученные по предложенной и стандартной методикам удовлетворительно совпадают и имеют лучшую воспроизводимость.

\section{ЗАКЛЮЧЕНИЕ}

Теоретически обоснованы и апробированы новые аналитические формы для косвенного атомноабсорбционного определения фосфора: 11-молибдожелезофосфатный гетерополикомплекс и фенантролинатный комплекс меди(II) (3:1) с ГПА, которые обеспечивают снижение предела обнаружения, ускорение и упрощение методики. Изучены оптимальные условия образования и отделения (экстракционного и флотационного) предложенных комплексных соединений. Исследованы мешающие влияния и оптимальные условия атомно-абсорбционного определения элементов-маркеров - меди и железа. Разработана методика косвенного пламенного атомно-абсорбционного определения фосфора в воде, отличающаяся от ранее известных лучшими метрологическими характеристиками. Предел обнаружения 0.005 мг/л, относительное стандартное отклонение 0.06 , время определения 35 мин.

\section{СПИСОК ЛИТЕРАТУРЫ}

1. Afkhami A., Norooz-Asl R. // Journal of Hazardous Materials, 2009, vol. 167, pp. 752-755. DOI: 10.1016/j. jhazmat.2009.01.039

2. Al-Shwaiyat M.E.A., Vishnikin A.B., Chmilenko F.А. // Вопросы химии и хим. технологии, 2005, № 2, c. $9-13$.

3. Ganesh S., Ahmed M. K., Velavendan P., et al. // Water Science \& Technology, 2012, vol. 66, pp. 2653-2658. DOI: $10.2166 /$ wst.2012.468

4. Uemura T., Ogusu T., Takeuchi M., et al. // Analytical Sciences, 2010, vol. 26, pp. 797-801. DOI: 10.2116/analsci. 26.797
5. Liu R., Ishimatsu R., Yahiro M., et al. // Talanta, 2015, vol. 132, pp. 96-105. DOI: 10.1016/j.talanta.2014.08.057

6. Hurford T. R., Boltz D. F. // Analytical Chemistry, 1968, vol. 40, № 2, pp. 379-382. DOI: 10.1021/ ac60258a019

7. Jacubiec R., Boltz D. F. // Analytical Chemistry, 1968, vol. 40, № 2, pp. 446-449. DOI: 10.1021/ac60258a052

8. Lueck C. H., Boltz D. F. // Analytical Chemistry, 1958, vol. 30, № 2, pp. 183-185. DOI: 10.1021/ac60134a006

9. Simon S. J., Boltz D. F. // Analytical Chemistry, 1975, vol. 47, № 11, pp. 1758-1762. DOI: 10.1021/ac60361a010

10. Аль-Швейят М. И. А., Вишникин А. Б., Чмиленко Ф. А. // Вопросы химии и хим. технологии, 2004, № 2, c. $9-12$.

11. Вишникина Е. В., Вишникин А. Б., Чмиленко Ф. А. // Вопросы химии и хим. технологии, 2003, № 1, c. $14-18$.

12. Lajunen L. H. J., Perämäki P. Spectrochemical analysis by atomic absorption and emission. $2^{\text {nd }}$ ed., RSC, 2004, 360 p. DOI: 10.1039/9781847551900-00078

13. Lobinski R., Marczenko Z. Spectrochemical Trace Analysis for Metals and Metalloids. Amsterdam: Elsevier, 1996, vol. 30, 808 p.

14. Taga M., Kan M. // Talanta, 1989, vol. 36, № 9, pp. 955-956. DOI: $10.1016 / 0039-9140(89) 80037-2$

15. Бургер К. Органические реагенты в неорганическом анализе. М.: Мир, 1975, $272 \mathrm{c}$.

16. ISO 6878:2004 Water quality - Determination of phosphorus - Ammonium molybdate spectrometric method - Geneva: ISO, 2004, 28 p.

17. Шкаравский Ю. Ф. // Украинский химический журнал, 1965, т. 31, № 1, с. 94-100.

18. Дрогомирецкая О. А., Шкаравский Ю. Ф., Пилипенко А. Т. // Журнал неорганической химии, 1971, т. 16, c. 2736-2742.

19. Пилипенко А. Т., Шкаравский Ю. Ф., Драгомирецкая О. А. // Украинский химический журнал, 1971, т. 37, № 6-8, c. 815-820.

20. Бабко А. К. Физико-химический анализ комплексных соединений в растворах (Оптический метод). Киев: ИАН УССР, 1955, 328 с. 
21. Buckley R. I., Clark R. J. H. // Coordination Chemistry Reviews, 1985, vol. 65, pp. 167-218. DOI: $10.1016 / 0010-8545(85) 85025-6$

22. Wery A. S. J., Gutiérrez-Zorrilla J. M., Luque A., et al. // Polyhedron, 1997, vol. 16, № 15, pp. 2589-2597. DOI: 10.1016/S0277-5387(97)00008-9

23. Briand L. E., Valle G. M., Thomas H. J. // Journal of Materials Chemistry, 2002, vol. 12, № 2, pp. 299-304. DOI: 10.1039/B106769A
24. Himeno S., Maeda K., Osakai T., et al. // Bulletin of the Chemical Society of Japan, 1993, vol. 66, № 1, pp. 109-113. DOI: 10.1246/bcsj.66.109

25. Федоров А. А., Черняховская Ф. В., Вернидуб А. С., и др. Аналитическая химия фосфора. М.: Наука, 1974, 220 c.

\title{
MODIFICATION OF ANALYTICAL FORMS IN INDIRECT ATOMIC- ABSORPTION DETERMINATION OF PHOSPHORUS
}

\author{
(C) 2018 A. S. Alemasova, N. D. Shchepina, A. N. Chuprina, A. S. Sergeeva, A. V. Dobrydin \\ Donetsk National University, 24 University str., 83001 Donetsk, Ukraine \\ e-mail:alemasovaa@gmail.com \\ Received 06.08.2018
}

\begin{abstract}
The new analytical forms for indirect atomic absorption determination of phosphorus - the 11-molybdoironphosphate heteropolycomplex and ion associate of copper(II) phenantrolinate- molybdophosphate - were theoretical substantiated and tested which provide the lower detection limit, acceleration and simplification of the technique. Optimal conditions of the formation and separation (extraction and flotation) of the proposed complex compounds were studied.

The indirect atomic absorption method of phosphorus determination point is to bind of phosphate ions to a stable complex compounds with a marker element and then to determine marker element concentration using atomic absorption method determination and to calculate the analyte concentration using the concentration of the marker element.

Optimal conditions for ion associate flotation were established for the analytical form of the ion associate of copper(II) phenanthrolinate complex with molybdophosphate anion: the solution acidity is in $\mathrm{pH}$ range from 2.5 to 3.5 , the concentration ratio of ammonium molybdate and copper phenantrolinate(II) is $80: 1$. It has been found that the proposed analytical form provides better selectivity while phosphorus determination. The 500 -fold excess of $\mathrm{Na}^{+}, \mathrm{K}^{+}, \mathrm{Ca}^{2+}, \mathrm{Mg}^{2+}, \mathrm{W}(\mathrm{VI}), \mathrm{S}_{2} \mathrm{O}_{3}^{2-}$, $\mathrm{NO}_{3}^{-}, \mathrm{Cd}^{2+}$ does not influence.

As for analytical form based on the triple metal-substituted phosphorus heteropolyanion using iron(III) as metal-indicator the extraction separation was used. The extractants and solvents of various types (alcohols, esters, ketones) were investigated. It was found that the best extractants are butan-2-one and cyclohexanone. The most suitable solvent for direct flame atomic absorption iron determination in the extract is butan-2-one. The iron analytical signal in the butan-2-one medium is 1.4 times more in comparison with the aqueous solution increases while it is 1.3 times less in cyclohexanone.

The indirect flame atomic absorption phosphorus determination technique in water was developed, which differs from the known before by improved reproducibility, speed, selectivity. The detection limit is 0.005 $\mathrm{mg} / \mathrm{l}$, the relative standard deviation does not exceed 0.06 , the analysis duration is 35 minutes.
\end{abstract}

Keywords: phosphorus, indirect determination, atomic absorption spectrometry/

DOI: https://doi.org/10.17308/kcmf.2018.20/577

\section{REFERENCES}

1. Afkhami A., Norooz-Asl R. Journal of Hazardous Materials, 2009, vol. 167, pp. 752-755. DOI: 10.1016/j. jhazmat.2009.01.039

2. Al-Shwaiyat M. E. A., Vishnikin A. B., Chmilenko F. A. Voprosy khimii i khimicheskoi tekhnologii [Issues of Chemistry and Chemical Technology], 2005, no. 2, pp. 9-13. (in Russ.)

3. Ganesh S., Khan Fahmida, Ahmed M. K., Velavendan P., Pandey N. K., Kamachi Mudali U. Water Science \& Technology, 2012, vol. 66, pp. 2653-2658. DOI: 10.2166/ wst.2012.468 
4. Uemura T., Ogusu T., Takeuchi M., Tanaka H. Analytical Sciences, 2010, vol. 26, pp. 797-801. DOI: 10.2116/ analsci.26.797

5. Liu R., Ishimatsu R., Yahiro M., Adachi C., Nakano K., Imato T. Talanta, 2015, vol. 132, pp. 96-105. DOI: 10.1016/j.talanta.2014.08.057

6. Hurford T. R., Boltz D. F. Analytical Chemistry, 1968, vol. 40, no. 2, pp. 379-382. DOI: 10.1021/ac60258a019

7. Jacubiec R., Boltz D. F. Analytical Chemistry, 1968, vol. 40, no. 2, pp. 446-449. DOI: 10.1021/ac60258a052

8. Lueck C. H., Boltz D. F. Analytical Chemistry, 1958, vol. 30, no. 2, pp. 183-185. DOI: 10.1021/ac60134a006

9. Simon S. J., Boltz D. F. Analytical Chemistry, 1975, vol. 47 , no. 11, pp. 1758-1762. DOI: $10.1021 /$ ac60361a010

10. Al'-Shvejjat M. I. A., Vishnikin A. B., Chmilenko F. A. Voprosy khimii i khimicheskoi tekhnologii [Issues of Chemistry and Chemical Technology], 2004, no. 2, pp. 9-12. (in Russ.)

11. Vishnikina E. V., Vishnikin A. B., Chmilenko F. A. Voprosy khimii i khimicheskoi tekhnologii [Issues of Chemistry and Chemical Technology], 2003, no. 1, pp. 14-18. (in Russ.)

12. Lajunen L. H. J., Perämäki P. Spectrochemical Analysis by Atomic Absorption and Emission. $2^{\text {nd }}$ ed., RSC, 2004, 360 p. DOI: 10.1039/9781847551900-00078

13. Lobinski R., Marczenko Z. Spectrochemical Trace Analysis for Metals and Metalloids. Amsterdam: Elsevier, 1996, vol. 30, 808 p.

14. Taga M., Kan M. Talanta, 1989, vol. 36, no. 9, pp. 955-956. DOI: 10.1016/0039-9140(89)80037-2

15. Burger K. Organicheskie reagenty v neorganicheskom analize. [Organic Reagents in Inorganic Analysis]. Moscow, Mir Publ., 1975, 272 p. (in Russ.)
16. ISO 6878:2004 Water quality - Determination of phosphorus - Ammonium molybdate spectrometric method - Geneva: ISO, 2004, 28 p.

17. Shkaravskij Ju. F. Ukrainskij himicheskij zhurnal [Ukrainian Chemistry Journal], 1965, vol. 31, no. 1, pp. 94100. (in Ukr.)

18. Drogomireckaja O. A., Shkaravskij Ju. F., Pilipenko A. T. Zhurnal neorganicheskoj himii [Russian Journal of Inorganic Chemistry], 1971, vol. 16, pp. 2736-2742. (in Russ.)

19. Pilipenko A. T., Shkaravskij Ju. F., Dragomireckaja O. A Ukrainskij himicheskij zhurnal [Ukrainian Chemistry Journal], 1971, vol. 37, no. 6-8, pp. 815-820. (in Ukr.)

20. Babko A. K. Fiziko-himicheskij analiz kompleksnyh soedinenij $v$ rastvorah (Opticheskij metod). [PhysicoChemical Analysis of Complex Compounds in Solutions (Optical Method)]. Kiev: IAN USSR Publ., 1955, 329 p. (in Russ.)

21. Buckley R. I., Clark R. J. H. Coordination Chemistry Reviews, 1985, vol. 65, pp. 167-218. DOI: 10.1016/00108545(85)85025-6

22. Wery A. S. J., Gutiérrez-Zorrilla J. M., Luque A., Ugalde M., Román P. Polyhedron, 1997, vol. 16, no. 15, pp. 2589-2597. DOI: 10.1016/S0277-5387(97)00008-9

23. Briand L. E., Valle G. M., Thomas H. J. Journal of Materials Chemistry, 2002, vol. 12, no. 2, pp. 299-304. DOI: 10.1039/B106769A

24. Himeno S., Maeda K., Osakai T., Saito A., Hori T. Bulletin of the Chemical Society of Japan, 1993, vol. 66, no. 1, pp. 109-113. DOI: 10.1246/bcsj.66.109

25. Fedorov A. A., Chernjahovskaja F. V., Vernidub A. S., Ananevskaja M. P., Zamaraev V. P. Analiticheskaja himija fosfora. [Analytical Chemistry of Phosphorus]. Moscow, Nauka Publ., 1974, 220 p. (in Russ.)
Алемасова Антонина Сергеевна - д. х. н., профессор, заведующий кафедрой аналитической химии, Донецкий национальный университет; тел.: +7(863) 308250, затем 0713217740, e-mail: alemasovaa@gmail.com

Щепина Наталья Дмитриевна - к. х. н., доцент кафедры аналитической химии, Донецкий национальный университет; e-mail: shnatalina@mail.ru

Чуприна Анастасия Никоаевна - магистр кафедры аналитической химии, Донецкий национальный университет; e-mail: 74doninu@gmail.ru

Сергеева Анастасия Сергеевна - магистр кафедры аналитической химии, Донецкий национальный университет; e-mail: anastasia-sergeeva1995@mail.ru

Добрыдин Александр Ввладимирович - с. н. с. кафедры аналитической химии, Донецкий национальный университет; e-mail: av_dobrydin@mail.ru
Antonina S. Alemasova - Dr. Sci. (Chem.), Professor, Head of Analytical Chemistry Department, Donetsk National University; tel.: +7(863) 308250, then 0713217740, e-mail: alemasovaa@gmail.com

Natalia D. Shchepina - Cand. Sci. (Chem.), Associate Professor, Analytical Chemistry Department, Donetsk National University; e-mail: shnatalina@ mail.ru

Anastasia N. Chuprina - master, Analytical Chemistry Department, Donetsk National University; e-mail: 74doninu@gmail.ru

Anastasia S. Sergeeva - master, Analytical Chemistry Department, Donetsk National University; e-mail: anastasia-sergeeva1995@mail.ru

Aleksandr V. Dobrydin - Senior Researcher, Analytical Chemistry Department, Donetsk National University; e-mail: av_dobrydin@mail.ru 